\title{
A METHOD FOR THE DETERMINATION OF THE VOLUME OF AIR IN THE LUNGS: MEASUREMENTS IN CHRONIC PULMONARY EMPHYSEMA *
}

\author{
By G. EMMANUEL, W. A. BRISCOE AND A. COURNAND
}

\author{
(From the Department of Medicine, Columbia University College of Physicians and Surgeons, \\ and the Cardio-Pulmonary Laboratory of the First Medical and Chest Services, Columbia \\ University Division, Bellevue Hospital, New York, N. Y.)
}

(Submitted for publication July 15, 1960; accepted September 23, 1960)

The present study is concerned with the measurement of the functional residual capacity (FRC) in chronic pulmonary emphysema by a gas dilution method, i.e., the washout of nitrogen from the lung during prolonged oxygen breathing.

There have been many methods in use to measure the FRC (or the residual volume) since Davy in 1800 measured his own residual volume by rebreathing hydrogen, which he had made himself, from a balloon (1). These methods, both the open circuit (washout) and closed circuit (rebreathing from a balloon or spirometer), have in general followed a consistent historic trend in that longer and longer periods of washout or rebreathing have been required in later methods: Davy in 1800 rebreathed for $20 \mathrm{sec}-$ onds (1), Gréhant in 1864 for 6 inspirations (2), Van Slyke and Binger in 1923 for 5 minutes (3), Christie and Bates for 7 minutes $(4,5)$, Darling, Cournand and associates for 7 or 11 minutes $(6,7)$ and Briscoe, Becklake and Rose for 12 minutes $(8,9)$. In justice to these earlier workers it should be mentioned that most of those quoted above and others $(10,11)$ realized that to get the best results in emphysema somewhat longer studies were desirable.

More recent studies of the $\mathrm{N}_{2}$ or helium washout in patients with chronic pulmonary emphysema have found detectable quantities of these inert gases being washed out of the lungs, distinct from those washed out from tissues, even after 20 to 40 minutes of $\mathrm{O}_{2}$ breathing (12-18).

The present study describes a method in which all the $\mathrm{N}_{2}$ eliminated from the lung during 15 minutes, or longer, of oxygen breathing is measured. Moreover, the quantity of $\mathrm{N}_{2}$ which would be eliminated in a longer study is esti-

* This investigation was supported by a research grant (Public Health Service Grant H-2001 C) from the National Heart Institute, Bethesda, Md. mated by integrating the exponential washout function in the least ventilated alveoli. The advantage of this procedure lies in eliminating the need for an alveolar sample to estimate the $\mathrm{N}_{2}$ remaining in the lung at the end of the study. Such samples are misleadingly low in $\mathrm{N}_{2}$ in chronic pulmonary emphysema and result in underestimation of the FRC.

\section{METHODS}

Functional residual capacities were measured by the conventional method of Cournand, Baldwin, Darling and Richards (7). They were also measured at a different time by a new method to be described here. This method is a development both of that used by Blair, Hickam and Frayzer with helium $(14,15)$ and by Briscoe and associates with $\mathrm{N}_{2}$ (19). It utilizes a system of two balloons (Figure 1) which collect the gas expired in alternate 30 -second periods. At the end of each 30 -second collection, the balloon is emptied into the Tissot spirometer by pressing it between two boards suspended on either side of it. The mixed expired gas expelled from each balloon in turn is analyzed with a $\mathrm{N}_{2}$ meter. Thus, every 30 seconds the volume expired and the mean concentration of $\mathrm{N}_{2}$ in that volume are known. The study ends after 15 to $25 \mathrm{~min}$ utes.

I. Nitrogen washout curve. Figure 2 shows the data in one study in which there were 32 balloon collections during 16 minutes of $\mathrm{O}_{2}$ breathing. In each collection the volume measured on the Tissot spirometer and the difference between the inspired $\mathrm{N}_{2}$ concentration and that of the mixed expired gas in the balloon were measured. Their product yields the quantity of $\mathrm{N}_{2}$ eliminated from the body in that half minute. By subtracting the quantity of $\mathrm{N}_{2}$ eliminated from the tissues $\left(\dot{V}^{\prime} N_{2}\right)$ in each period, the quantity of $N_{2}$ eliminated from the lungs $\left(\dot{\mathrm{V}}_{2}\right)$ in each period was determined and plotted on semilogarithmic paper.

At the beginning of $\mathrm{O}_{2}$ breathing, $\dot{\mathrm{V}}_{2}$ is momentarily about 81 per cent of expired gas volume ( $\dot{\mathrm{V} E})$. In the first 5 minutes it falls steeply due to the rapid washout of $\mathrm{N}_{2}$ from the well ventilated groups of alveoli. After about 5 minutes $\dot{\mathrm{V}}_{2}$ is still considerable and only slowly decreasing. This is due to the extremely small ventilation of a large group of alveoli whose volume and ventilation can be estimated from a straight line drawn through this slow phase. The major part of the total $\mathrm{N}_{2}$ initially present in 


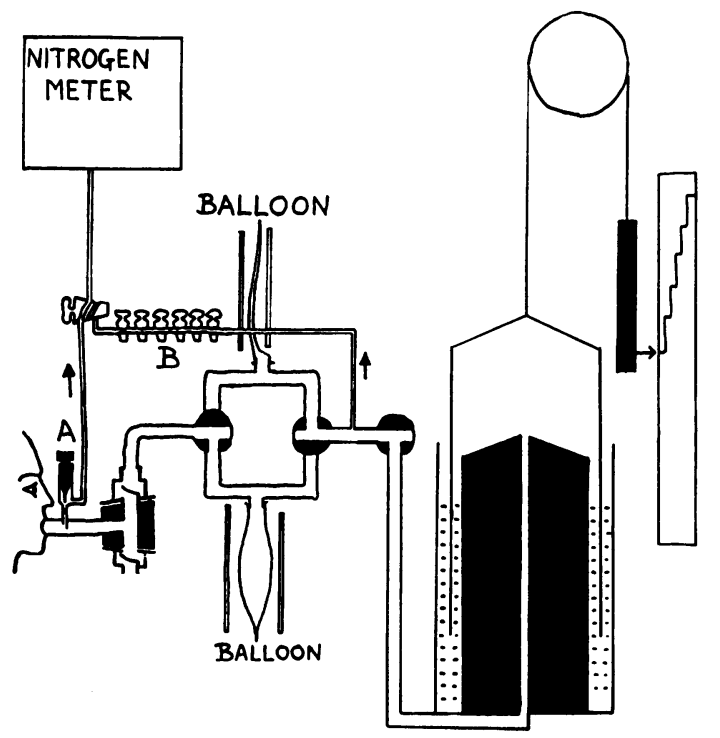

Fig. 1. Schematic Representation of the equipMENT USED IN THE PRESENT STUDY. The needle valve (A) samples at the mouth, and the long line, with glass stopcock leak (B), samples mixed expired air; the balloon stopcock assembly is made from anesthesia balloons and standard plumbing fittings. The valve box at the mouth is part of a 5-way stopcock (Respiration Aids, 255 E. 148 St., New York 51, N. Y.) here shown connected for oxygen breathing. When the mouthpiece is connected to air as the inspirate, the expirate goes to waste; these two channels used during air breathing are not shown here.

the lungs was determined without assumptions by adding the 32 measurements obtained in 16 minutes $\left(\int_{0}^{16} \dot{V}_{N_{2}} \cdot d t\right)$. The smaller quantity which would have been washed out thereafter was estimated by extrapolating the slow phase and integrating to determine $\int_{16}^{\infty} \dot{\mathrm{V}}_{\mathrm{N}_{2}} \cdot \mathrm{dt}$ under the straight line in Figure 2.

II. Details of equipment and procedure. The dead spaces of the two anesthesia balloons used were 250 and $330 \mathrm{ml}$, these being the volumes of the tubes between the mouth and the balloons. To correct for this dead space the midpoint of each collection should be taken to be about 4 seconds earlier than the middle of the 30 -second period. This has a negligible effect in studies on patients with chronic pulmonary emphysema. Both balloons were flushed with medical oxygen before each study, until the $\mathrm{N}_{2}$ meter showed that the gas leaving the balloon contained no more than 0.025 per cent more $\mathrm{N}_{2}$ than the medical oxygen, this figure being the limit of resolution of our $\mathrm{N}_{2}$ meter.

The stopcocks controlling admission and displacement of gases alternately to and from the balloons were mechanically linked, so that when either balloon was connected to the Tissot spirometer, the other was automatically connected to the mouth. These stopcocks and their associated $\mathrm{T}$ and $\mathrm{L}$ pieces are standard $\frac{3}{4}$ inch plumbing supplies.

Inspired and expired gas were sampled for about 15 seconds in each half-minute period through a needle valve at the mouth. The conventional needle valve type of leak into the vacuum system of the $\mathrm{N}_{2}$ meter has the advantage of quick response, but it is unreliable for accurate analysis since it is sensitive to changes in hydration and temperature, and to blockage by air-suspended particles. For the analysis of mixed expired gas in the balloons, 6 glass stopcocks connected in series gave a more reliable leak with a line delay of 3 seconds and a 90 per cent response time of half a second, when adjusted to produce a pressure in the vacuum system of $2 \mathrm{~mm}$.

The $\mathrm{N}_{2}$ meter was calibrated before and at the end of each study with known gas mixtures (air, medical $\mathrm{O}_{2}$, and 2.2, 8.6, 16.6 and 42 per cent $\mathrm{N}_{2}$ in $\mathrm{O}_{2}$ ).

Sources of nitrogen other than the lungs were controlled as follows. None of the subjects had perforated ear drums. They were instructed not to belch or to allow leaks at the mouthpiece and their mouths were watched continuously by a second observer. Between balloon analyses the $\mathrm{N}_{2}$ meter was connected to sample inspired and expired gas at the mouth for about 15 seconds in every half-minute period. The record of $\mathrm{N}_{2}$ concentration at the mouth obtained via the needle valve showed no leaks.

III. Symbols. It is useful here to comment on the symbols used in this report. They are the same as those used previously in this laboratory (18-20), except in these respects: $\dot{V}^{\prime} N_{2}$ is the rate of nitrogen elimination from tissues, and $\dot{\mathrm{V}}_{2}$ is the rate of nitrogen elimination from

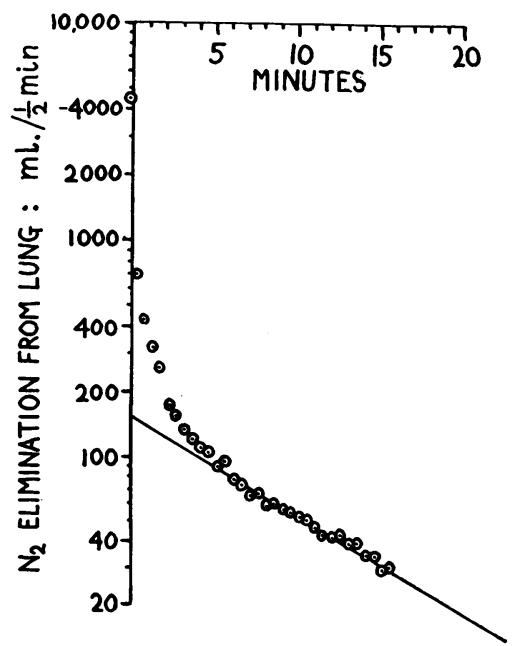

Fig. 2. DATA in ONE STUdy ON a PATIENT With CHRONIC PULMONARY EMPHYSEMA. The abscissa shows the duration of $\mathrm{O}_{2}$ breathing in minutes. The ordinate shows milliliters of $\mathrm{N}_{2}$ at BTPS eliminated from the lungs in each half minute collection plotted on a logarithmic scale and corrected for tissue $\mathrm{N}_{2}$. The line represents the extrapolated washout from the lungs after 16 minutes. The point before zero time represents the quantity of $\mathrm{N}_{2}$ expired per half minute while the subject is breathing air. 
TABLE I

Quantities of $\mathrm{N}_{2}$ eliminated by a $70 \mathrm{~kg}$ man, in milliliters of $N_{2} B T P S^{*}$ during periods ending at the times indicated

\begin{tabular}{lccc}
\hline \hline Time & $\begin{array}{c}\text { Quantity/ } \\
\text { 30 sec }\end{array}$ & Time & $\begin{array}{c}\text { Quantity/ } \\
60 \mathrm{sec}\end{array}$ \\
\hline $\min$ & $m l N_{2}$ & $\min$ & $\operatorname{ml~N2}$ \\
0.5 & 36 & 8 & 22 \\
1.0 & 24 & 9 & 21 \\
1.5 & 22 & 10 & 20 \\
2 & 21 & 11 & 19 \\
2.5 & 19 & 12 & 19 \\
3 & 18 & 13 & 18 \\
3.5 & 17 & 14 & 17 \\
4 & 16 & 15 & 17 \\
4.5 & 15 & 16 & 16 \\
5 & 13 & 17 & 15 \\
5.5 & 13 & 18 & 15 \\
6 & 12 & 19 & 15 \\
6.5 & 12 & 20 & 14 \\
7 & 12 & 21 & 14 \\
& & &
\end{tabular}

* These conditions are applicable to calculations of FRC. Volume $($ BTPS $)=$ volume $($ STPD $) \times 1.21$.

lungs corrected for elimination from tissues, i.e., $\dot{\mathrm{V}}_{2}=$ $\dot{V} E\left(F E-F_{I}\right)-\dot{V}^{\prime} N_{2}$. Whenever the symbol $F$ is used for a gas concentration the chemical symbol is omitted, it being understood that we always refer to $\mathrm{N}_{2}$ concentrations. A superscript refers to the time in minutes at which a rate of elimination or a concentration applies. Subscripts 1, 2 and 3 apply as before to phases or groups of alveoli with decreasing ventilation. $M$ is the number of minutes in which a group of alveoli washes out 90 per cent of its $N_{2}$. $\quad \dot{V}^{\prime}$ is the flow rate from a group of alveoli at one instant during expiration and $\dot{V}$ is ventilation per minute, integrated over many breaths. $\mathrm{F}_{\mathbf{A}^{\prime}}$ is a gas concentration at the end of a forced expiration and $F_{\bar{A}}$ is mean alveolar gas concentration, weighted by the volume of the differently ventilated alveoli.

IV. Tissue $\mathrm{N}_{2}$ elimination. Thirty-minute washout studies on 5 normal subjects confirmed the rates of tissue $\mathrm{N}_{2}$ elimination found by Robertson, Siri and Jones (12) and validated the use of our $\mathrm{N}_{2}$ meter at low $\mathrm{N}_{2}$ concentrations. Table I shows the rates of $\mathrm{N}_{2}$ elimination used in calculating our data, which apply for a $70 \mathrm{~kg}$ man, and were therefore adjusted in proportion to the weight of each subject. These rates agree with the figures for $\mathrm{N}_{2}$ elimination in 7 minutes already in use in this laboratory $(21,22)$.

$V$. Check on the method. In determining, by the use of balloons, the quantity of $\mathrm{N}_{2}$ eliminated from the lungs over any given period, it is necessary to add the quantities in many balloon collections. The sum of so many quantities, each being a product of a volume and a concentration read from a calibration curve, might have a large error were there a small systematic error in each collection. Therefore, in 3 patients, as well as in a group of normal subjects not described here, the volume of lung $\mathrm{N}_{2}$ eliminated both between 0 and 7 and between 7 . and 15 minutes of $\mathrm{O}_{2}$ breathing was simultaneously measured in three different ways as a check on the method: 1 ) by summating the quantities of $\mathrm{N}_{2}$ measured every half minute in the balloon collections by $\mathrm{N}_{2}$ meter analysis and Tissot volume record between 0 and 7 and between 7 and 15 minutes; 2) by collecting expired gases getween 0 and 7 and 7 and 15 minutes in two different Tissot spirometers and analyzing the mixed gas in each spirometer by means of the $\mathrm{N}_{2}$ meter; and 3) by analyzing gas samples from the same two spirometers with the Van Slyke apparatus.

Thus, in each subject there were two gas collections in which the quantity of $\mathrm{N}_{2}$ eliminated from the lungs in 7 minutes was measured in three different ways. These three different methods of measurement agreed: the standard deviation of the various methods from the mean for all three was $99 \mathrm{ml} \mathrm{N}_{2}$ BTPS in the 0 to 7 minute collection when the total quantity of $\mathrm{N}_{2}$ averaged $3,479 \mathrm{ml}$, and $87 \mathrm{ml} \mathrm{N} \mathrm{N}_{2}$ in the 7 to 15 minute period when the total quantity averaged $1,035 \mathrm{ml}$.

An additional check on the method is afforded by measurement of the quantities of $\mathrm{N}_{2}$ eliminated in 7 minutes at different times by methods 1 and 3 in all 11 cases. Here, too, as is apparent from Table III, there is agreement within 10 per cent.

\section{RESULTS}

All 11 patients were disabled by severe chronic pulmonary emphysema with or without a bronchitic element. Their physical characteristics and maximal breathing capacity (MBC) are given in Table II. The results in this group will be presented under two main headings: 1) the quantities of $\mathrm{N}_{2}$ eliminated, as measured by different methods at various times during $\mathrm{O}_{2}$ breathing, and the estimates of the FRC derived therefrom ; 2) the relative volume and ventilation of the least ventilated alveoli and their gas composition after 7 minutes of $\mathrm{O}_{2}$ breathing.

I. Quantities of $\mathrm{N}_{2}$ eliminated from lungs and FRC measurement. The FRC is the quantity of $\mathrm{N}_{2}$ initially present in the lungs at the end of a resting expiration divided by 81 per cent, a

TABLE II

Physical characteristics and maximal breathing capacity $(M B C)$ in 11 patients with chronic pulmonary emphysema

\begin{tabular}{lccc}
\hline \hline Subject & Age & BSA & MBC \\
\hline & $y r s$ & $m^{2}$ & $L / m i n$ \\
W.D. & 61 & 1.64 & 16 \\
M.L. & 40 & 1.35 & 15 \\
W.H. & 58 & 1.50 & 20 \\
A.Mc. & 54 & 1.48 & 18 \\
O.H. & 66 & 1.85 & 18 \\
S.G. & 55 & 1.50 & 19 \\
J.J. & 67 & 1.57 & 14 \\
L.L. & 52 & 1.59 & 19 \\
C.Gy. & 56 & 1.46 & 16 \\
C.Gi. & 60 & 1.77 & 46 \\
T.L. & 58 & 1.53 & 19 \\
Mean & 57 & 1.57 & 20 \\
\hline
\end{tabular}


TABLE III

Quantities of $\mathrm{N}_{2}$ eliminated and the FRC: Comparison between new method and conventional method in 11 cases of chronic pulmonary emphysema

\begin{tabular}{|c|c|c|c|c|c|c|c|}
\hline \multirow{3}{*}{$\begin{array}{l}\text { Subject } \\
\text { W.D. }\end{array}$} & \multicolumn{4}{|c|}{ Quantities of $\mathrm{N}_{2}$ eliminated* } & \multirow{3}{*}{$\begin{array}{c}\text { FRC } \\
m l \\
6,933 \\
{[5,245]}\end{array}$} & \multirow{2}{*}{\multicolumn{2}{|c|}{$\begin{array}{l}\text { Differences between two } \\
\text { estimates of FRC }\end{array}$}} \\
\hline & \multirow{2}{*}{$\begin{array}{c}\begin{array}{c}0-7 \\
\min \end{array} \\
m l \\
3,623 \\
{[3,823]}\end{array}$} & \multirow{2}{*}{\begin{tabular}{|c|}
$\begin{array}{c}7-15 \\
\min \end{array}$ \\
$m l$ \\
1,324
\end{tabular}} & \multirow{2}{*}{$\begin{array}{c}\begin{array}{c}15-\infty \\
\min \end{array} \\
m l \\
669\end{array}$} & \multirow{2}{*}{$\begin{array}{c}\begin{array}{c}0-\infty \\
\min \end{array} \\
m l \\
5,616\end{array}$} & & & \\
\hline & & & & & & $\begin{array}{c}m l \\
1,688\end{array}$ & $\begin{array}{l}\% \\
32\end{array}$ \\
\hline M.L. & $\begin{array}{c}2,335 \\
{[2,125]}\end{array}$ & 686 & 383 & 3,404 & $\begin{array}{c}4,202 \\
{[2,847]}\end{array}$ & 1,355 & 48 \\
\hline W.K. & $\begin{array}{c}3,752 \\
{[3,725]}\end{array}$ & 932 & 225 & 4,909 & $\begin{array}{c}6,060 \\
{[5,094]}\end{array}$ & 966 & 19 \\
\hline A.Mc. & $\begin{array}{c}2,517 \\
{[2,313]}\end{array}$ & 433 & 173 & 3,123 & $\begin{array}{c}3,856 \\
{[3,052]}\end{array}$ & 804 & 26 \\
\hline O.H. & $\begin{array}{c}4,190 \\
{[4,215]}\end{array}$ & 1,224 & 816 & 6,230 & $\begin{array}{c}7,691 \\
{[6,222]}\end{array}$ & 1,469 & 24 \\
\hline S.G. & $\begin{array}{c}2,687 \\
{[2,485]}\end{array}$ & 663 & 350 & 3,700 & $\begin{array}{c}4,567 \\
{[3,396]}\end{array}$ & 1,171 & 34 \\
\hline J.J. & $\begin{array}{c}3,449 \\
{[3,461]}\end{array}$ & 1,089 & 326 & 4,864 & $\begin{array}{c}6,005 \\
{[4,873]}\end{array}$ & 1,132 & 23 \\
\hline L.L. & $\begin{array}{c}2,740 \\
{[2,610]}\end{array}$ & 826 & 537 & 4,103 & $\begin{array}{c}5,065 \\
{[3,505]}\end{array}$ & 1,560 & 45 \\
\hline C.Gy. & $\begin{array}{c}4,429 \\
{[3,995]}\end{array}$ & 948 & 612 & 5,989 & $\begin{array}{c}7,393 \\
{[5,368]}\end{array}$ & 2,025 & 38 \\
\hline C.Gi. & $\begin{array}{c}2,497 \\
{[2,637]}\end{array}$ & 999 & 533 & 4,029 & $\begin{array}{c}4,974 \\
{[3,600]}\end{array}$ & 1,374 & 38 \\
\hline T.L. & $\begin{array}{c}2,903 \\
{[2,985]}\end{array}$ & 836 & 545 & 4,284 & $\begin{array}{c}5,289 \\
{[4,053]}\end{array}$ & 1,236 & 30 \\
\hline Mean & $\begin{array}{c}3,192 \\
{[3,125]}\end{array}$ & 905 & 470 & 4,568 & $\begin{array}{c}5,639 \\
{[4,296]}\end{array}$ & 1,344 & 32 \\
\hline
\end{tabular}

* All quantities of $\mathrm{N}_{2}$ are at BTPS and corrected for $\mathrm{N}_{2}$ from tissues. Figures in brackets are those obtained by the conventional method.

figure considered to correspond to the initial concentration of $\mathrm{N}_{2}$ in the lungs. The quantity initially present theoretically corresponds to the quantity collected during the washout with $\mathrm{O}_{2}$. This quantity, and hence the FRC, were determined by the conventional and by the new method. These determinations are summarized in Table III.

The first four columns of this table give the respective quantities of $\mathrm{N}_{2}$ eliminated from the lungs: from 0 to 7 minutes, $\int_{0}^{7} \mathrm{VN}_{2} \cdot \mathrm{dt}$; from 7 to 15 minutes, $\int_{7}^{15} \mathrm{VN}_{2} \cdot \mathrm{dt}$; from 15 to $\infty \mathrm{min}$ utes, $\int_{15}^{\infty} \mathrm{VN}_{2} \cdot \mathrm{dt}$; and from 0 to $\infty$ minutes, the total amount of $\mathrm{N}_{2}$ eliminated from the lungs if the study had continued indefinitely. These figures are corrected for the $\mathrm{N}_{2}$ elimination from tissues and are based on the half-minute balloon collections. The lower figures in the first column are the quantities of $\mathrm{N}_{2}$ eliminated from lungs as measured in the Tissot spirometer by the conventional method. Although measured on a different occasion, these data agree well with the results of the balloon collection. The data in column 3 are derived from the plotted $\mathrm{N}_{2}$ washout curve by algebraic integration of the extrapolation of the slow phase from the end of the study to infinity:

$$
\int_{15}^{\infty} \mathrm{VN}_{2} \cdot \mathrm{dt}={ }^{15} \mathrm{VN}_{2} \cdot \mathrm{M}_{3} / 2.3
$$

where $M_{3}$ is the time taken for the slow phase to fall through one logarithmic cycle, 2.3 is $\log _{e} 10$, and ${ }^{15} \mathrm{VN}_{2}$ is the rate of $\mathrm{N}_{2}$ elimination from the lungs at 15 minutes.

It can be seen from the mean values that in patients with severe emphysema only 70 per cent of the lung's $\mathrm{N}_{2}$ is eliminated in the first $7 \mathrm{~min}$ - 
utes of $\mathrm{O}_{2}$ breathing, 20 per cent between 7 and 15 minutes and the remaining 10 per cent thereafter.

The FRC determined by the quantity of $\mathrm{N}_{2}$ eliminated during prolonged washout is $\int_{0}^{\infty} \mathrm{VN}_{2}$ $\cdot \mathrm{dt} / 0.81$. It has an average value of $5,639 \mathrm{ml}$. The FRC determined by the conventional method is $\left(\int_{0}^{7} \mathrm{VN}_{2} \cdot \mathrm{dt}\right) \div\left(0.81-{ }^{7} \mathrm{FA}^{\prime}\right)$ and has an average value of $4,296 \mathrm{ml}$. The new method gives an FRC which ranges between 0.804 and $2.025 \mathrm{~L}$ higher than the conventional method, with a mean difference of $1.344 \mathrm{~L}$; the percentage difference ranges between 19 and 48 per cent, with a mean difference of 32 per cent.

In Table IV are given some other lung volumes which are derived from the FRC. Values based on the conventional method are listed between parentheses. Significantly, the residual volume/ total lung capacity (RV/TLC) ratio is relatively little affected by these large changes in both volumes $(1.4 \mathrm{~L})$, its average value increasing

\begin{tabular}{|c|c|c|c|}
\hline Subject & $\mathrm{RV}^{*}$ & TLC* & RV/TLC* \\
\hline W.D. & $\begin{array}{c}L \\
6.2 \\
{[4.4]}\end{array}$ & $\begin{array}{c}L \\
8.6 \\
{[6.8]}\end{array}$ & $\begin{array}{c}\% \\
72 \\
{[64]}\end{array}$ \\
\hline M.L. & $\begin{array}{c}3.1 \\
{[1.7]}\end{array}$ & $\begin{array}{c}5.2 \\
{[3.8]}\end{array}$ & $\begin{array}{c}59 \\
{[45]}\end{array}$ \\
\hline A.Mc. & $\begin{array}{c}3.5 \\
{[2.6]}\end{array}$ & $\begin{array}{c}5.2 \\
{[4.3]}\end{array}$ & $\begin{array}{c}67 \\
{[61]}\end{array}$ \\
\hline O.H. & $\begin{array}{c}6.9 \\
{[5.4]}\end{array}$ & $\begin{array}{c}9.0 \\
{[7.5]}\end{array}$ & $\begin{array}{c}77 \\
{[72]}\end{array}$ \\
\hline J.J. & $\begin{array}{c}5.4 \\
{[4.2]}\end{array}$ & $\begin{array}{c}7.0 \\
{[5.9]}\end{array}$ & $\begin{array}{c}77 \\
{[72]}\end{array}$ \\
\hline L.L. & $\begin{array}{c}3.9 \\
{[2.8]}\end{array}$ & $\begin{array}{c}5.7 \\
{[4.6]}\end{array}$ & $\begin{array}{c}69 \\
{[62]}\end{array}$ \\
\hline C.Gy. & $\begin{array}{c}6.7 \\
{[4.7]}\end{array}$ & $\begin{array}{c}8.4 \\
{[6.3]}\end{array}$ & $\begin{array}{c}80 \\
{[73]}\end{array}$ \\
\hline C.Gi. & $\begin{array}{c}4.3 \\
{[2.9]}\end{array}$ & $\begin{array}{c}7.9 \\
{[6.4]}\end{array}$ & $\begin{array}{c}63 \\
{[44]}\end{array}$ \\
\hline T.L. & $\begin{array}{c}4.2 \\
{[2.9]}\end{array}$ & $\begin{array}{c}6.6 \\
{[5.4]}\end{array}$ & $\begin{array}{c}62 \\
{[54]}\end{array}$ \\
\hline Mean & $\begin{array}{c}4.9 \\
{[3.5]}\end{array}$ & $\begin{array}{c}7.0 \\
{[5.7]}\end{array}$ & $\begin{array}{c}70 \\
{[62]}\end{array}$ \\
\hline
\end{tabular}

* The upper figures are derived from the FRC determined by the method described in this paper. The figures in brackets are based on the conventional method.
TABLE V

Relative volume $\left(\mathrm{L}_{3} / \mathrm{LT}\right)$ and ventilation $\left(\dot{\mathrm{V}}_{3} / \dot{\mathrm{V}} \mathrm{E}\right)$ of the least ventilated alveoli, and alveolar nitrogen concentrations

\begin{tabular}{lrrrrr}
\hline \hline & & \multicolumn{4}{c}{ Alveolar $\mathrm{N}_{2}$ concentrations* } \\
\cline { 5 - 6 } Subject & $\mathrm{L}_{3} / \mathrm{LT}$ & $\dot{\mathrm{V}}_{\mathrm{A}_{3}} / \dot{\mathrm{V}}^{\mathrm{E}}$ & $\mathrm{FA}_{3} \dagger$ & $\mathrm{F}_{\overline{\mathrm{A}} \dagger} \dagger$ & $\mathrm{FA}^{\prime} \dagger$ \\
\hline & $\%$ & $\%$ & $\%$ & $\%$ & $\%$ \\
W.D. & 84 & 11 & 32 & 28 & 8.1 \\
M.L. & 67 & 6 & 39 & 26 & 6.3 \\
W.H. & 68 & 9 & 23 & 16 & 7.8 \\
A.Mc. & 64 & 6 & 24 & 15 & 5.2 \\
O.H. & 74 & 6 & 36 & 27 & 13.2 \\
S.G. & 74 & 7 & 30 & 22 & 7.8 \\
J.J. & 74 & 10 & 29 & 22 & 9.9 \\
L.L. & 76 & 5 & 36 & 27 & 6.5 \\
C.Gy. & 58 & 5 & 37 & 21 & 6.6 \\
C.Gi. & 76 & 3 & 40 & 30 & 7.7 \\
T.L. & 67 & 3 & 37 & 24 & 7.4 \\
Mean & 71 & 6 & 33 & 23 & 7.9 \\
& & & &
\end{tabular}

* After $7 \mathrm{~min}$ of $\mathrm{O}_{2}$ breathing.

$+\mathrm{FA}_{3}$ alveolar $\mathrm{N}_{2}$ concentration in least ventilated alveoli $; \mathrm{F} \overline{\mathrm{A}}$, mean alveolar $\mathrm{N}_{2}$ concentration in all alveoli; $\mathrm{FA}^{\prime}$, alveolar $\mathrm{N}_{2}$ concentration estimated by forced expiration.

from 62 per cent with the conventional method to 70 per cent with the new method.

II. Characteristics of the least ventilated alveoli and their effects upon alveolar gas composition after 7 minutes of $\mathrm{O}_{2}$ breathing. Table $\mathrm{V}$ gives two parameters determined by the slow phase of the washout curve (19): $\mathrm{L}_{3} / \mathrm{LT}$ is the fraction of the FRC which is very poorly ventilated and $\mathrm{VA}_{3} / \mathrm{VE}$ is the fraction of expired ventilation which comes from these spaces. On the average, 71 per cent of the FRC was ventilated by 6 per cent of the minute ventilation. These characteristics have a profound effect upon the significance and validity of alveolar gas sampled after 7 minutes of $\mathrm{O}_{2}$ breathing.

The concentration of $\mathrm{N}_{2}$ in the least ventilated alveoli after 7 minutes of $\mathrm{O}_{2}$ breathing $\left({ }^{7} \mathrm{~F}_{\mathrm{A}_{3}}\right)$ is estimated from the washout rate of the slow phase :

$$
{ }^{7} \mathrm{~F}_{\mathrm{A}_{3}}=0.81 \times \mathrm{e}^{-(7 \times 2.3) / \mathrm{M} 3} .
$$

It ranges from 23 to 40 per cent with a mean of 33 per cent. The true mean alveolar $\mathrm{N}_{2}$ concentration $\left({ }^{7} \bar{F} \bar{A}\right)$ at this time, when the more ventilated alveoli contain negligible concentrations, is ${ }^{7} \mathrm{FA}_{3} \times \mathrm{L}_{3} / \mathrm{LT}$. This ranges from 15 to 30 per cent with a mean of 23 per cent. The forced mixed alveolar sample $\left(\mathrm{FA}^{\prime}\right)$ at this time ranges from 5.2 to 13.2 per cent with a mean of 7.9 per cent. 


\section{DISCUSSION}

I. The magnitude of the discrepancy. There is a large discrepancy, up to $2.0 \mathrm{~L}$, in the FRC measured by the two methods in patients with emphysema. It is worthwhile to establish this firmly, since some earlier studies found that the $\mathrm{N}_{2}$ washout curve yielded essentially the same FRC, even in emphysema, as did the conventional method (13). This discrepancy is not due to differences in measurements of quantities of $\mathrm{N}_{2}$ eliminated from the lungs as shown by Table III. Furthermore, measurements in normal subjects, not described here, showed good agreement between the two methods. This discrepancy is largely due to the fact that the conventional method uses a forced expiration to estimate the average concentration of $\mathrm{N}_{2}$ remaining in the lung after 7 minutes of $\mathrm{O}_{2}$ breathing. Moreover, it has been shown that the least ventilated alveoli, which constitute on the average 71 per cent of the FRC, are ventilated by only 6 per cent of the minute ventilation (Table V). In order that the forced alveolar sample be representative for the measurement of the FRC, it is necessary that these alveoli contribute 71 per cent of the gas in this sample. If they did so, this sample $\left({ }^{7} \mathrm{~F} \overline{\mathrm{A}}\right)$ would, on the average, contain 23 per cent $N_{2}$. The forced alveolar sample $\left({ }^{7} \mathrm{FA}^{\prime}\right)$, with a mean composition of 7.9 per cent $\mathrm{N}_{2}$, therefore grossly underestimates the mean $\mathrm{N}_{2}$ concentration in the lungs after 7 minutes of $\mathrm{O}_{2}$ breathing.

Studies of the alveolar $\mathrm{N}_{2}$ concentration after a single breath of $\mathrm{O}_{2}$ have clearly shown that the least ventilated alveoli contribute more to the expirate at the end of the forced expiration (23, 24). From such data it is not possible to determine how much more they contribute, since the $\mathrm{N}_{2}$ concentration within the differently ventilated alveoli is not measured. The $\mathrm{N}_{2}$ washout method permits an estimate of the $\mathrm{N}_{2}$ concentration in the least ventilated alveoli after $7 \mathrm{~min}$ utes of $\mathrm{O}_{2}$ breathing. Hence, we can determine how much these alveoli contribute to the sample taken at the end of a forced expiration.

$$
\begin{aligned}
\mathrm{FA}^{\prime}=\left(\dot{\mathrm{V}}_{3}^{\prime} \mathrm{F}_{\mathrm{A}_{3}}+\right. & \dot{\mathrm{V}}^{\prime}{ }_{2} \mathrm{~F}_{\mathrm{A}_{2}} \\
& \left.+\dot{\mathrm{V}}^{\prime}{ }_{1} \mathrm{~F}_{\mathrm{A}_{1}}\right) /\left(\dot{\mathrm{V}}^{\prime}{ }_{1}+\dot{\mathrm{V}}_{2}{ }_{2}+\dot{\mathrm{V}}^{\prime}{ }_{3}\right)
\end{aligned}
$$

where $\dot{V}^{\prime}$ refers to an instantaneous flow rate at the end of the expiration, and the subscripts re- fer to groups of alveoli. Since $F_{A_{2}}$ and $F_{A_{1}}$ are practically zero at 7 minutes of $\mathrm{O}_{2}$ breathing

$$
\mathrm{FA}^{\prime} / \mathrm{FA}_{3}=\mathrm{V}^{\prime}{ }_{3} /\left(\mathrm{V}_{1}^{\prime}+\mathrm{V}^{\prime}{ }_{2}+\mathrm{V}^{\prime}{ }_{3}\right) \text {. }
$$

Using our mean values, this ratio is $7.9 / 33=24$ per cent. In other words, the poorly ventilated alveoli, which in this study constitute 71 per cent of the FRC, contribute only 24 per cent of the gas expired at the end of a forced expiration.

While this is four times as much as the 6 per cent which these alveoli contribute to mixed expired gas, it is not enough to make the forced expiratory sample a valid one. The better ventilated alveoli, which constitute only 29 per cent of the lung volume, still contribute 76 per cent of the gas expired, even at the end of a forced expiration. The use of such an alveolar sample to estimate the quantity of $\mathrm{N}_{2}$ remaining in an unevenly ventilated lung must lead to an underestimate of the FRC. The only question is as to the degree of underestimation. This, in severe chronic pulmonary emphysema, is as indicated in Table III.

II. Validity of high FRC's in the literature. Determination of the FRC by mixing an inert gas into a spirometer of decreasing volume (due to oxygen consumption) tended to overestimate the FRC in patients with chronic pulmonary emphysema (4). This was due to the " $\mathrm{N}_{2}$ lag" phenomenon $(25,26)$. However, from time to time, very high estimates of the FRC by valid methods in the hands of careful workers are found in patients with chronic pulmonary emphysema, and published. This applies both to the closed (27) and the open circuit methods $(12,14,15,18,19)$ and especially when the studies are prolonged. In the past, values over $6 \mathrm{~L}$ have sometimes been presented apologetically by their authors and subject to a certain amount of skepticism. They have, for example, been attributed to leaks at the mouth or in the equipment used, to belching of abdominal gas, or to perforated ear drums. It was believed that the FRC in emphysema could not exceed the TLC of a normal lung (28). It now seems that some of these very large FRC's may, in fact, be acceptable measurements.

III. The concept of trapped gas. DuBois, Bedell and associates $(29,30)$, in comparing the thoracic gas volume measured by a body plethys- 
mographic method (31) with the FRC measured by the conventional method, found that the latter was less by an amount which varied between 0.69 and $2.38 \mathrm{~L}$ in emphysematous subjects. At that time they attributed their higher values by the plethysmographic method to trapped gas. They conceived that there were alveoli which were closed and which therefore did not wash out $\mathrm{N}_{2}$, although they did, like freely communicating alveoli, affect the compressibility of the lung by the chest wall when the shutter at the mouth was closed. It now seems that if great care is taken to collect and measure all the $\mathrm{N}_{2}$ washed out of the alveoli in prolonged $\mathrm{O}_{2}$ breathing, a discrepancy of the same order of magnitude is observed. In the present study, the new method gave values which exceeded those of the conventional method by between 0.828 and $2.082 \mathrm{~L}$. This suggests that the present method is measuring the same lung spaces as did the plethysmographic method.

That these spaces are included in the $\mathrm{FRC}$, as measured in the present study, indicates that their gas is not completely trapped. Any gasfilled space in the body must be replenished from time to time if it is not to collapse; the spaces we measure must also contribute to expired gas, not necessarily at every breath but at some times during 15 minutes. In some patients with large cysts in otherwise normal lungs, we have observed that there are variations in the $\mathrm{N}_{2}$ washout curve, suggesting that some pulmonary spaces empty intermittently at intervals of several minutes. This has been observed by others also (32). We regard these spaces as ventilated, not as reservoirs of trapped gas, even though they do not contribute to expired gas at every breath.

$I V$. The time needed between studies. The quantity of $\mathrm{N}_{2}$ eliminated in successive conventional FRC determinations in this laboratory indicates that in chronic pulmonary emphysema the second study showed a smaller quantity of $\mathrm{N}_{2}$ eliminated. This review applied to paired studies in each of 15 consecutive cases with emphysema both in 1940 and in 1958. The mean differences were 8.6 per cent of the total quantity of $\mathrm{N}_{2}$ in 1940, and 9.0 per cent in 1958. A waiting period of half an hour between studies was usually allowed. This seems to be inadequate in emphysema, and a waiting period of at least 1 hour between duplicate determinations of FRC is now being used with the new open circuit method.

$V$. Relative merits of various methods used for the measurement of FRC. The open circuit method described here has the advantage of giving a more accurate estimate of the volume of the lungs in emphysema than the conventional method, which is in error by as much as 48 per cent in this series. It should be pointed out that when Cournand and co-workers (7) developed the conventional method, they were very much aware of the possibility of such an error in patients with emphysema. They measured the discrepancy between wash-in and washout FRC determinations, which is due to poor distribution and inadequate representation by the terminal forced expiration sample. In their subject, M.K., there was a discrepancy of 865 $\mathrm{ml}$ at 7 minutes, which fell to $590 \mathrm{ml}$ when the study was continued for 11 minutes (6). This is in the lower part of the range of the discrepancies discussed here.

The mean values in Table II show that in a typical case of severe chronic pulmonary emphy'sema about 70 per cent of the lung's nitrogen has been washed out in 7 minutes and about 90 per cent is washed out in 15 minutes. If the 7 -minute alveolar sample were in fact representative, it should indicate that 30 per cent of the nitrogen initially present still remains in the lungs, i.e., it would have a value of about 24 per cent in a typical case. In fact, this is more than the highest values which are actually observed. Alveolar samples at the end of a 7-minute washout can lead to large errors; but if a 15-minute collection were made, at which time a typical case has washed out 90 per cent of the nitrogen initially present, a low alveolar sample could cause an error of, at most, 10 per cent of the FRC. However, if 15 -minute washouts were done with the conventional Tissot method of collecting the gas, it would be necessary to use more, or larger, collecting spirometers and to analyze for very low concentrations of $\mathrm{N}_{2}$.

The method described here requires considerably more time, skill in handling of equipment, and calculation than the conventional method, and it may therefore be unsuitable for routine use. An alternative procedure is the body ple- 
thysmographic method (31). This recuires more instrumentation and more skill in maintenance and testing of equipment, but the duration of the study and the time spent in calculation is less. Good as this method is, however, it must underestimate, by about 30 per cent, the volume of lung spaces too large to allow rapid heat exchange between gas and tissue (33). To attain comparable accuracy in severe emphysema by the closed circuit helium dilution method, prolonged studies are necessary and the leakage or diffusion of helium from the circuit must be considered. It seems then that the measurement of the volume of air in the lungs of patients with severe chronic pulmonary emphysema presents an even greater challenge to our ingenuity than has been suspected heretofore. However, the method which at present seems the least open to objection is the one described here, which measures the total quantity of $\mathrm{N}_{2}$ initially present in the variously ventilated parts of these lungs, and washed out of them during $\mathrm{O}_{2}$ breathing.

\section{SUMMARY}

A method is described for collecting and measuring the quantity of $\mathrm{N}_{2}$ washed out of the lungs every half minute during oxygen breathing. The total quantity of $\mathrm{N}_{2}$ eliminated in 15 minutes of $\mathrm{O}_{2}$ breathing was measured in 11 patients with chronic pulmonary emphysema. The quantity of $\mathrm{N}_{2}$ which would have been eliminated in more prolonged studies was estimated by extrapolating the $\mathrm{N}_{2}$ washout curve. The functional residual capacity (FRC) so determined exceeded that obtained by conventional FRC measurements by between 0.804 and $2.025 \mathrm{~L}$. The magnitude of this discrepancy agrees well with that seen when body plethysmographic estimates are compared with conventional measurements of the FRC. It is suggested that this new method measures the volume of the same intrapulmonary spaces as does the body plethysmograph.

The composition of forced expiratory gas samples in chronic pulmonary emphysema is discussed.

\section{REFERENCES}

1. Davy, H. Researches, Chemical and Philosophical, Chiefly Concerning Nitrous Oxide, or Dephlogisticated Nitrous Air, and its Respiration. London, Johnson, 1800.
2. Grćhant, N. Recherches physiques sur la respiration de l'homme. J. Anat. (Paris) 1864, 1, 523.

3. Van Slyke, D. D., and Binger, C. A. L. Determination of lung volume without forced breathing. J. exp. Med. 1923, 37, 457.

4. Christie, R. V. The lung volume and its subdivisions. I. Methods of measurement. J. clin. Invest. 1932, 11, 1099.

5. Bates, D. V., and Christie, R. V. Intrapulmonary mixing of helium in health and in emphysema. Clin. Sci. 1950, 9, 17.

6. Darling, R. C., Cournand, A., and Richards, D. W., Jr. Studies on the intrapulmonary mixture of gases. III. An open circuit method for measuring residual air. J. clin. Invest. 1940, 19, 609.

7. Cournand, A., Baldwin, E. deF., Darling, R. C., and Richards, D. W., Jr. Studies on the intrapulmonary mixture of gases. IV. The significance of the pulmonary emptying rate and a simplified open circuit measurement of residual air. J. clin. Invest. 1941, 20, 681.

8. Briscoe, W. A., Becklake, M. R., and Rose, T. F. Intrapulmonary mixing of helium in normal and emphysematous subjects. Clin. Sci. 1951, 11, 45.

9. Briscoe, W. A. Further studies on the intrapulmonary mixing of helium in normal and emphysematous subjects. Clin. Sci. 1952, 11, 45.

10. Anthony, A. J. Untersuchung uber Lungenvolumina und Lungenventilation. Dtsch. Arch. klin. Med. 1930, 167, 129.

11. Gilson, J. C., and Hugh-Jones, P. The measurement of total lung volume and breathing capacity. Clin. Sci. 1949, 7, 185.

12. Robertson, J. S., Siri, W. E., and Jones, H. B. Lung ventilation patterns determined by analysis of nitrogen elimination rates; use of the mass spectrometer as a continuous gas analyzer. J. clin. Invest. 1950, 29, 577.

13. Fowler, W. S., Cornish, E. R., Jr., and Kety, S. S. Lung function studies. VIII. Analysis of alveolar ventilation by pulmonary $\mathrm{N}_{2}$ clearance curves. J. clin. Invest. 1952, 31, 40.

14. Blair, E., and Hickam, J. B. Quantitative study of intrapulmonary gas mixing in emphysema. Amer. J. Med. 1955, 18, 519.

15. Hickam, J. B., Blair, E., and Frayser, R. An opencircuit helium method for measuring functional residual capacity and defective intrapulmonary gas mixing. J. clin. Invest. 1954, 33, 1277.

16. Bouhuys, A., Jönsson, R., and Lundin, G. Nonuniformity of pulmonary ventilation in chronic diffuse obstructive emphysema. Acta med. scand. 1958, $162,29$.

17. Luft, U. C., Roorbach, E. H., and MacQuigg, R. E. Pulmonary nitrogen clearance as a criterion of ventilatory efficiency. Amer. Rev. Tuberc. 1955, $72,465$.

18. Briscoe, W. A., and Cournand, A. Uneven ventilation of normal and diseased lungs studied by an opencircuit method. J. appl. Physiol. 1959, 14, 284. 
19. Briscoc, W. A., Cree, E., Filler, J., Houssay, H., and Cournand, A. Distribution of the ventilation and perfusion to the emphysematous lung. J. appl. Physiol. 1960, 15, 285.

20. Comroe, J. H., Cournand, A., Ferguson, J. K. W., Filley, G. F., Fowler, W. S., Gray, J. S., Helmholtz, H. F., Jr., Otis, A. B., Pappenheimer, J. R., Rahn, H., and Riley, R. L. Standardization of definitions and symbols in respiratory physiology. Fed. Proc. 1950, 9, 602.

21. Darling, R. C., Cournand, A., Mansfield, J. S., and Richards, D. W., Jr. Studies on the intrapulmonary mixture of gases. I. Nitrogen elimination from blood and body tissues during high oxygen breathing. J. clin. Invest. 1940, 19, 591.

22. Cournand, A., Yarmush, I. G., and Riley, R. L. Influence of body size on gaseous nitrogen elimination during high oxygen breathing. Proc. Soc. exp. Biol. (N. Y.) 1941, 48, 280.

23. Fowler, W. S. Lung function studies. III. Uneven ventilation in normal subjects and in patients with pulmonary disease. J. appl. Physiol. 1949, 2, 283.

24. Comroe, J. H., Jr., and Fowler, W. S. Lung function studies. VI. Detection of uneven alveolar ventilation during a single breath of oxygen. Amer. J. Med. 1951, 10, 408 .

25. Lassen, H. C. A., Cournand, A., and Richards, D. W., Jr. Distribution of respiratory gases in a closed breathing circuit. I. Normal subjects. J. clin. Invest. 1937, 16, 1.
26. Cournand, A., Iassen, II. C. A., and Richards, D. W. Distribution of respiratory gases in a closed circuit. II. Pulmonary fibrosis and emphysema. J. clin. Invest. 1937, 16, 9.

27. Mounsey, J. P. D., Ritzmann, L. W., Selverstone, N. J., Briscoe, W. A., and McLemore, G. A. Circulatory changes in severe pulmonary emphysema. Brit. Heart J. 1952, 14, 153.

28. Christie, R. V. Emphysema of the lungs. Brit. med. J. 1944, 1, 105.

29. DuBois, A. B., Botelho, S. Y., Bedell, G. N., Marshall, R., and Comroe, J. H., Jr. A rapid plethysmographic method for measuring thoracic gas volume: A comparison with a nitrogen washout method for measuring functional residual capacity in normal subjects. J. clin. Invest. 1956, 35, 322.

30. Bedell, G. N., Marshall, R., DuBois, A. B., and Comroe, J. H., Jr. Plethysmographic determination of the volume of gas trapped in the lungs. J. clin. Invest. 1956, 35, 664.

31. Comroe, J. H., Jr., Botelho, S. Y., and DuBois, A. B. Design of a body plethysmograph for studying cardiopulmonary physiology. J. appl. Physiol. $1959,14,439$.

32. Wolf, W. A., and Carlson, L. D. Studies of pulmonary capacity and mixing with the nitrogen meter. J. clin. Invest. 1950, 29, 1568.

33. Briscoe, W. A., and DuBois, A. B. The relationship between airway resistance, airway conductance and lung volume in subjects of different age and body size. J. clin. Invest. 1958, 37, 1279. 